\title{
Numerical study on the effects of blood perfusion and tumor metabolism on tumor temperature for targeted hyperthermia considering a realistic geometrical model of head layers using the finite element method
}

\author{
Adeleh Kazemi Alamouti ${ }^{1} \cdot$ Mohammad Reza Habibi $^{2} \cdot$ Mohammad Mazidi Sharfabadi $^{2} \cdot$ Hossein Akbari Lalimi $^{3}$
}

Received: 22 May 2020 / Accepted: 25 February 2021 / Published online: 16 March 2021

(c) The Author(s) 2021 OPEN

\begin{abstract}
The main aim of the present work is to determine the temperature distribution in the normal and cancerous tissues to achieve the desired condition of hyperthermia. Hyperthermia can be defined as the mild elevation of the temperature to $40-46^{\circ} \mathrm{C}$, which induces the cancer cell death and enhances the effects of the radiotherapy and chemotherapy. In the present research, the realistic geometry of the human head layers and the tumor are modelled, geometrically, and then simulated similar to the real samples of MRI images with the size of $5990 \mathrm{~mm}^{3}$. The temperature distribution in the tumor and healthy tissues was obtained based on the solution of Penne's bio-heat transfer equation utilizing the Finite Element scheme. Employing the accurate boundary conditions for the thermal simulation of the problem, two main layers of the human brain, namely, white matter (WM) and gray matter (GM), as well as the cerebrospinal fluid (CSF) and the skull, are considered in the thermal analysis. In order to examine the hyperthermia conditions, the effects of the different blood perfusion rates and tumor metabolism on the tumor temperature are analyzed. The results showed that by reducing the blood perfusion rate from 0.0016 to $0.0005(\mathrm{ml} /(\mathrm{ml} . \mathrm{s}))$, the temperature increased by nearly $0.2{ }^{\circ} \mathrm{C}$ at the center of the tumor implying that the variations of the blood perfusion rate in the tumor have not a significant influence on its temperature. Moreover, it was found that when the tumor metabolism increases five times (equal to $125 \times 10^{3} \mathrm{~W} / \mathrm{m}^{3}$ ) than its normal value (equal to $25,000 \mathrm{~W} / \mathrm{m}^{3}$ ), the temperature reaches to the range needed for ablation of the brain tumor $\left(40-46{ }^{\circ} \mathrm{C}\right)$. The results also indicated that the manipulation of the cancer tissues metabolic rate via thermal simulation could be efficiently employed to estimate the amount of heat needed for the thermal ablation of the tumor.
\end{abstract}

Keywords Tumor · Temperature distribution - Finite element method · Realistic brain model · Metabolism . Hyperthermia

\section{Introduction}

Brain temperature, as an independent therapeutic target variable, has received increasingly intense clinical attention. The impact of the brain temperature is prevalent in a number of common human diseases. This, generally means that efforts to understand the fundamental aspects of the brain temperature regulation are critical for the development of safe, effective, and pragmatic clinical treatments for patients with brain tumors [1]. However, it seems that there is no accurate numerical simulation exist for the temperature distribution in the human body and

\footnotetext{
$\triangle$ Mohammad Mazidi Sharfabadi, mazidim@ripi.ir | ${ }^{1}$ Mechanical Engineering Department, Islamic Azad University, West Tehran Branch, Tehran, Iran. ${ }^{2}$ Development and Optimization of Energy Technologies Division, Research Institute of Petroleum Industry (RIPI), Tehran, Iran. ${ }^{3}$ Department of Medical Physics, Faculty of Medicine, Mashhad University of Medical Sciences, Mashhad, Iran.
} 
the equations must be simplified by making assumptions. These assumptions must preserve the parameters and the main properties of the tissue.

As far as the heat transfer models in human body metabolism, some researchers have proposed different equations to study the heat transfer in vital tissues, including the Pennes bio-heat transfer equation [2], the Chen-Holmes model [3], the three-temperature model for peripheral tissue [4], and the Weinbaum-Jiji equation [5], which comes with specific applications and limitations. One of the limitations of the Pennes equation is the assumption of non-directional blood perfusion in the exchange of the energy between the veins and tissues. In addition, the local structure of capillaries was ignored; therefore, the energy exchange with arteries (larger blood vessels) was not considered. Generally, This equation (Pennes bio-heat transfer equation) is used in thermal simulation of the body and measuring the blood perfusion [6]. Unlike Pennes equation, the Chen-Holmes equation considers a balance between the blood and tissue in arteries, as well as the directional blood perfusion in the capillary geometry. Despite resolving the Pennes equation limitations to some extent, this model is still more difficult to analyze and is often used for capillary networks and blood perfusion [3]. The three-temperature model, considers the temperature in arteries, veins, and tissues. This equation also assumes directional blood flow for the thermal analysis and is mostly performed for peripheral tissues [7]. Similarly, to the previous one, solving equations by this method is also riddled with complexities. The Weinbaum-Jiji equation simplifies the three-temperature model, but still, it involves several variables and is relatively complex [5]. As discussed earlier, for the thermal simulation of body tissues, the Pennes equation is the most straightforward and practical option among the four cases.

Detection of cancerous tumors is one of the main objectives in the thermal simulation of vital tissues. On the other hand, the metabolism of cancerous cells is higher than the normal cells. Thus, as a general fact, the temperature of cancerous tissues is higher than that of the healthy tissues [8]. The thermal analysis serves a critical role in the thermal simulation and geometrical modelling of a tissue. Bousselham et al. [9] studied on the thermal analysis of the brain tumor for different sizes. They showed that the magnetic resonance parameters are highly temperature-dependent. They relied on Pennes bio-heat transfer equation to solve the temperature distribution in the brain tumor and modelled the brain in three layers of cerebrospinal fluid (CSF), gray matter (GM), and skull, as concentric spheres, with the spherical tumor was located at the center of this head model. Their results showed that in comparison with the normal tissue, the maximum temperature rise at the center of the tumor is $1.5^{\circ} \mathrm{C}$. Tang et al. [10] implemented the Penne's bio-heat transfer equation for hyperthermia purposes considering the blood perfusion rate term as a function of ambient temperature, and then solved it separately for both normal and tumor tissues. They also assumed a spherical shape for normal and tumor tissues. Bousselham et al. [11] presented a 3D model of the brain, representing normal tissues by a cuboid containing a spherical embedded tumor and used a genetic algorithm with the inverse solution technique to estimate the presence and dimensions of the tumor. Li et al. [12] conducted an analytical solution of Penne's bio-heat transfer equation to obtain the temperature distribution using a Laplace transform for hyperthermia treatment applications. They investigated the temperature distribution separately in the scalp and the brain matter. Their results showed that controlling the blood perfusion rate and the temperature inside the brain are useful for hyperthermia treatment purposes. They also simplified the geometry and assumed the tissue to be spherical. Majchrzak and Turchan [13] took into account the artery effects on the thermal simulation of tissues and solved the Pennes bio-heat transfer equation assuming a cubic geometry for both normal and tumor tissues. Kenna and Lakhssassi [14] used the Pennes bio-heat transfer equation for body tissues considering a linear temperature-dependent term for blood perfusion. Hossain and Mohammadi [15] applied an analytical solution to the Pennes bio-heat transfer equation for a cancerous tissue with spherical geometry. In a study by Kohani et al. [16] on the hyperthermia treatment of the cancerous tissues, the Pennes bio-heat transfer equation was employed for a spherical geometry. Bousselham, et al. [17] investigated the thermal analysis of brain tumor in an MRI image segmentation using finite difference method for discretization of Pennes bio-heat transfer equation. Considering various values for the blood perfusion and body metabolism, Shirkavand and Nazif [18] studies the temperature control of the human forearm under hyperthermia conditions. The effect of changing two aforementioned parameters (blood perfusion and body metabolism) on the temperature of a tumor and normal tissues was investigated in this study. 
From the above literature review, it can be concluded that the brain tissue is highly sensitive to the temperature fluctuations. Meanwhile, it seems that the scientific and clinical aspects of the brain in terms of spatial and temporal distribution of the temperature are not wellestablished yet. In the current research work, a realistic geometric model of the human brain, as well as the tumor is presented. Using a numerical simulation based on the finite element scheme, one may be to be able to conduct a variety of analyses at any points of the brain including the effects of the temperature variations.

In this paper, the brain and tumor's actual geometry are both applied. Bio-heat transfer equation with proper boundary conditions is solved numerically using FEM. The temperature profiles of a simple model of the brain and the real model are presented. Furthermore, the necessary temperature for hyperthermia by changing the volume of tumor metabolism and blood perfusion rate are also analyzed, and the temperature controlling process is presented.

\section{Mathematical modeling}

The human head consists of many regions with different layers. The schematic, location and the thermal properties of each layer of the head can be found in the literature [19]. Generally, brain matter, cerebrospinal fluid, skull, and scalp are the four main layers of the head. The brain matter contains both gray and white matters. In present work, three major layers of the head (brain matter, cerebrospinal fluid, skull) are modeled. These layers can be derived from the output of the geometric model, namely, the Menelik surface head mesh model. This file is available in an online database [20]. The geometry of the human head layers is demonstrated in Fig. 1. Here, the Pennes bio-heat transfer equation was solved under steady state conditions for all of the head layers considering appropriate thermo-physical properties and boundary conditions (Table 1). The general form of the Pennes bio-heat transfer equation can be expressed as follows [2]:

$\rho c \frac{\partial T}{\partial t}=\nabla \cdot(k \nabla T)-\rho_{b} c_{b} w_{b}\left(T-T_{b}\right)+Q_{m e t}$

where $\rho$ is the density of tissue, $c$ is the specific heat of tissue, $k$ is the thermal conductivity, $w_{b}$ is the blood perfusion rate, $\rho_{b}$ is the density of blood, $c_{b}$ is the specific heat of blood, $T_{b}$ is the temperature of blood, and $Q_{m e t}$ is the
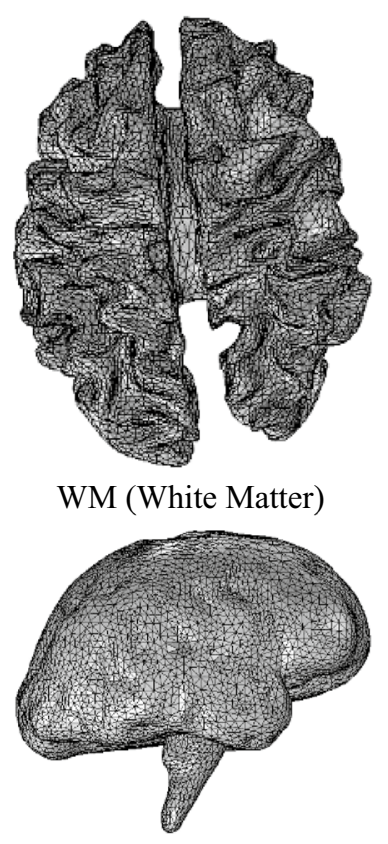

GM (Gray Matter)

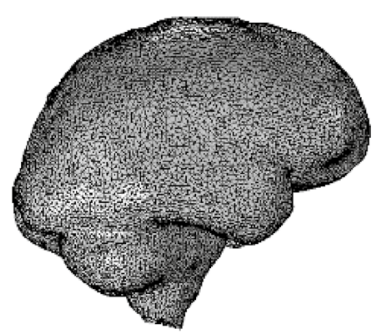

CSF (Cerebro Spinal Fluid)

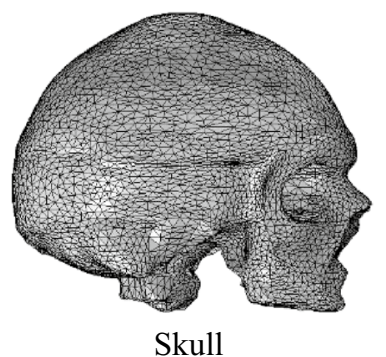

Fig. 1 Schematics of the three-dimensional (3D) geometry of the human head layers and surface meshing

metabolic heat generation. The physical properties of blood are $\rho_{b}=1052 \mathrm{~kg} / \mathrm{m}^{3}$ and $c_{b}=3800 \mathrm{~J} /\left(\mathrm{kg}{ }^{\circ} \mathrm{C}\right)$, and the temperature is assumed to be equal to $37^{\circ} \mathrm{C}$ [21].

From Eq. (1), it can be noted that obtaining an exact analytical solution for complex shapes like the human tissue is almost impossible [22]. Hence, different numerical 
Table 1 Physical properties of the head layers and the tumor

\begin{tabular}{lllllll}
\hline Material & $k\left[\mathrm{~W} /\left(\mathrm{m}^{\circ} \mathrm{C}\right)\right]$ & $\rho\left[\mathrm{kg} / \mathrm{m}^{3}\right]$ & $c_{p}\left[\mathrm{~J} /\left(\mathrm{kg}^{\circ} \mathrm{C}\right)\right]$ & $Q_{\text {met }}\left[\mathrm{W} / \mathrm{m}^{3}\right]$ & $w_{b}(\mathrm{ml} /(\mathrm{ml} . \mathrm{s}))$ & Refs \\
\hline Skull & 0.53 & 1850 & 1300 & 70 & 0.000143 & {$[9]$} \\
$\mathrm{CSF}^{\mathrm{a}}$ & 0.6 & 1000 & 4200 & 0 & 0 & {$[17]$} \\
$\mathrm{GM}^{\mathrm{b}}$ & 0.565 & 1035.5 & 3680 & 16,229 & 0.013289 & {$[17]$} \\
WM $^{\mathrm{c}}$ & 0.503 & 1027.4 & 3600 & 4517.9 & 0.003695 & {$[17]$} \\
Tumor & 0.565 & 1027.4 & 3600 & 25,000 & 0.0005 & {$[17]$} \\
\hline
\end{tabular}

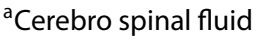

${ }^{\mathrm{b}}$ Gray matter

${ }^{c}$ White matter methods (finite element, finite volume, finite difference) are often utilized to solve differential equations with respect to the problem context. In present research, based on the Pennes bio-heat transfer equation, the temperature distribution of the so-called "Menelik head mesh model" is analyzed, numerically, via finite element scheme. As far as the structural analysis of the human body, it is very crucial to conduct any mechanical experiment. In recent years, many researchers has conducted the finite element method via numerical packages as powerful and effective tools to simulate the mechanical experiments related to the human body [23]. Developing the mesh formation, here, the surface elements are in triangular shape while the volumetric elements are of tetrahedron type.

\subsection{Boundary conditions}

In order to solve the Pennes equation, appropriate boundary conditions must be imposed to the problem domains. Temperature and the heat flux continuity conditions are set for the internal boundaries, as follows [24]:

$T_{1}=T_{2}$

$k_{1} \nabla \mathrm{T}=k_{2} \nabla \mathrm{T}$

while the convective boundary condition is assumed at the outer surface of the skull as [25]:

$-K \nabla T=h_{a}\left(T-T_{e}\right)$

where $h_{a}=8 \mathrm{Wm}^{-1} \mathrm{~K}^{-1}$, and the ambient temperature, $T_{e^{\prime}}$ is equal to $25^{\circ} \mathrm{C}$ [25].

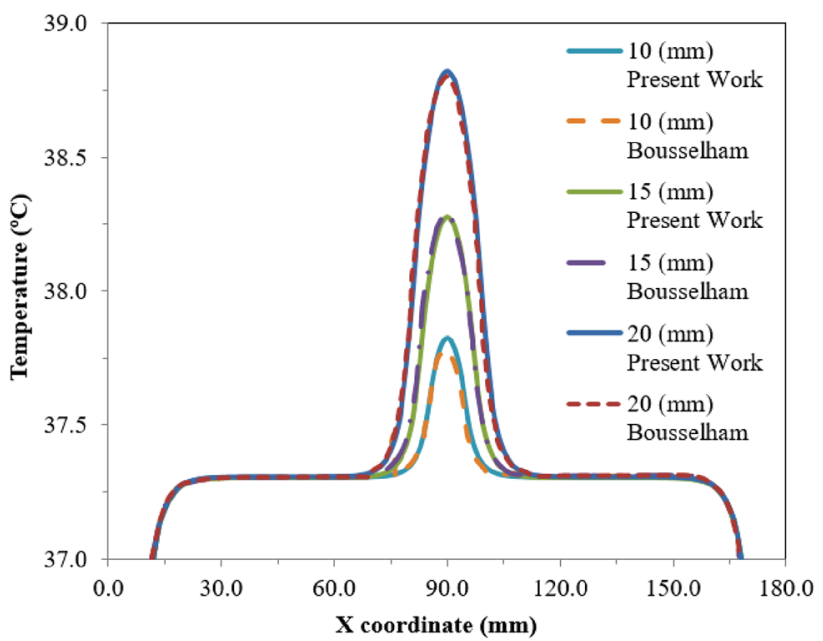

Fig. 2 Comparison between the present results of temperature distribution at the centerline of a tumor with those reported by Bousselham et al. [9] for tumors with three different diameters, namely, 10,15 , and $20 \mathrm{~mm}$

\section{Results and discussion}

\subsection{Validation}

In order to simulate the heat transfer inside the brain tissue, the head layers (CSF, GM, and skull) are considered as the concentric spheres. The spherical tumors with three different sizes were placed at the center of the head model. As far as the verification of the present model, the obtained results of the temperature distribution at the centerline of the tumors are compared to those of the Bousselham et al. [9] work for three different diameters, namely, 10, 15, and $20 \mathrm{~mm}$ (Fig. 2). As the figure shows, very good agreement exists between the results using the present FEM model and those reported by Bousselham et al.; however, they obtained the temperature 
Surface: Temperature $(\operatorname{deg} C)$ Max/Min Point: Temperature $(\operatorname{deg} C)$ $\mathrm{mm}$

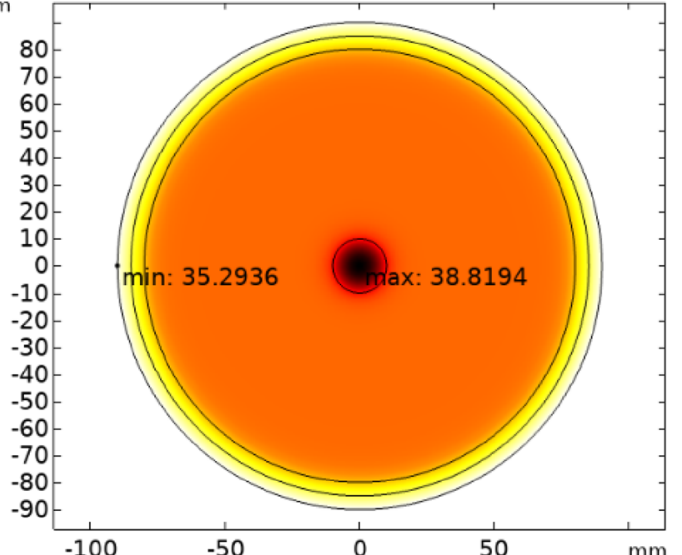

(a)

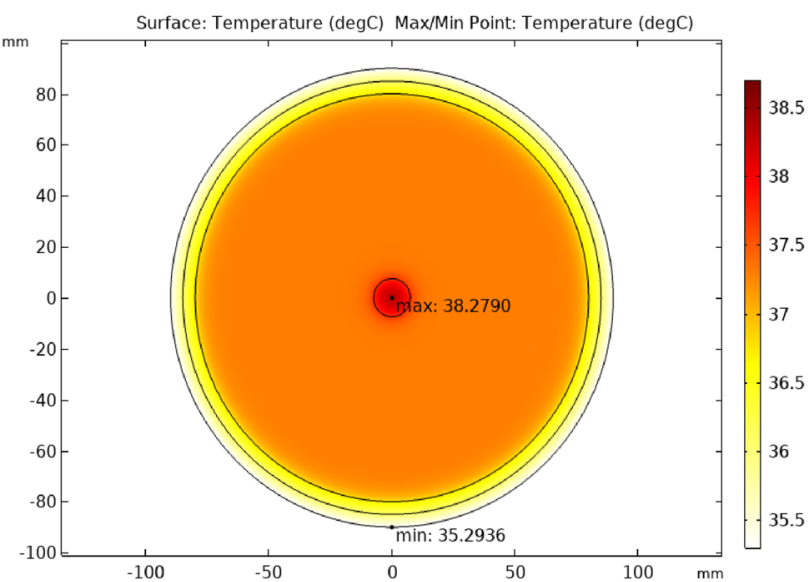

(b)

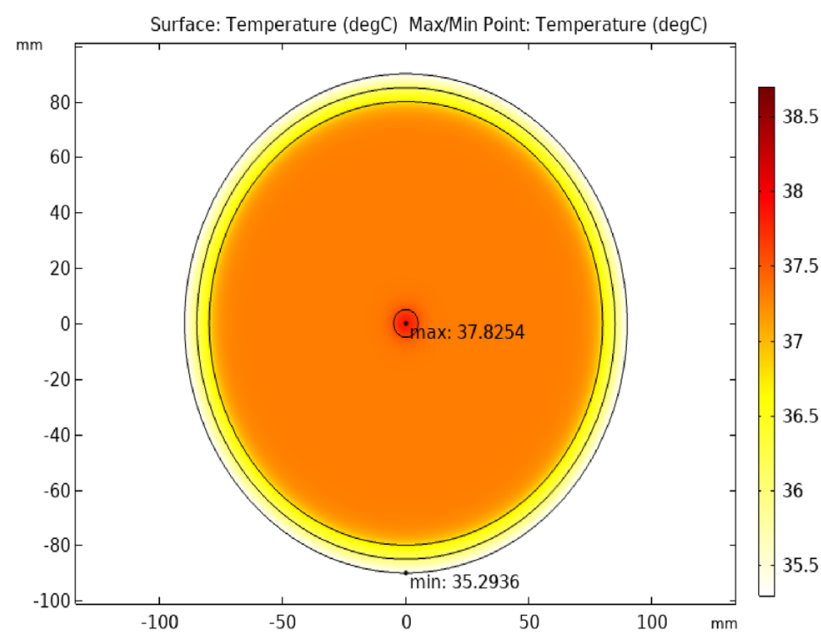

(c)

Fig. 3 Effect of tumor diameter on temperature distribution for three different diameters; a $20 \mathrm{~mm}, \mathbf{b} 15 \mathrm{~mm}$, c $10 \mathrm{~mm}$

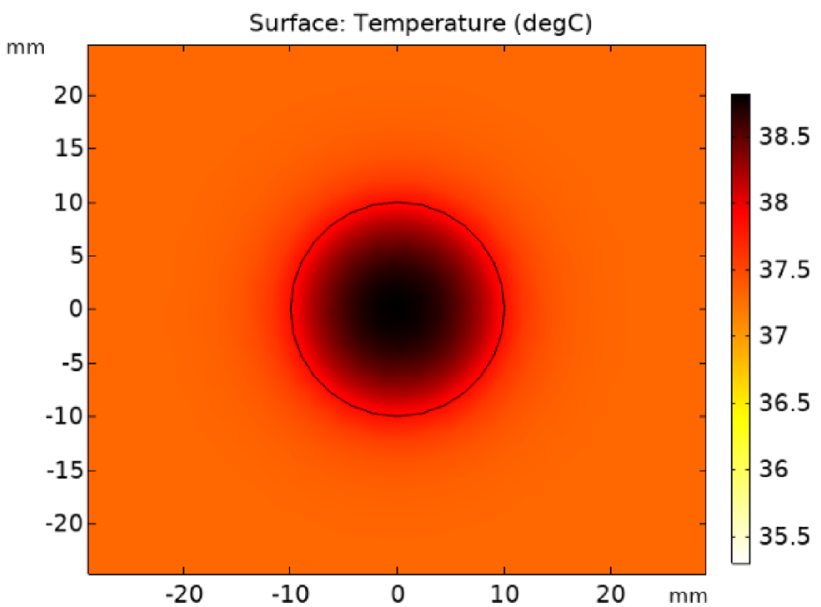

(a)

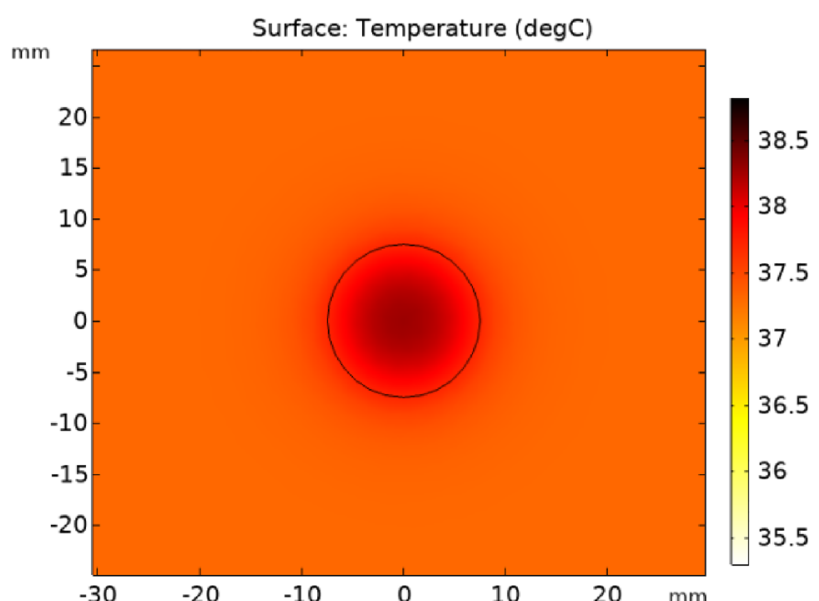

(b)

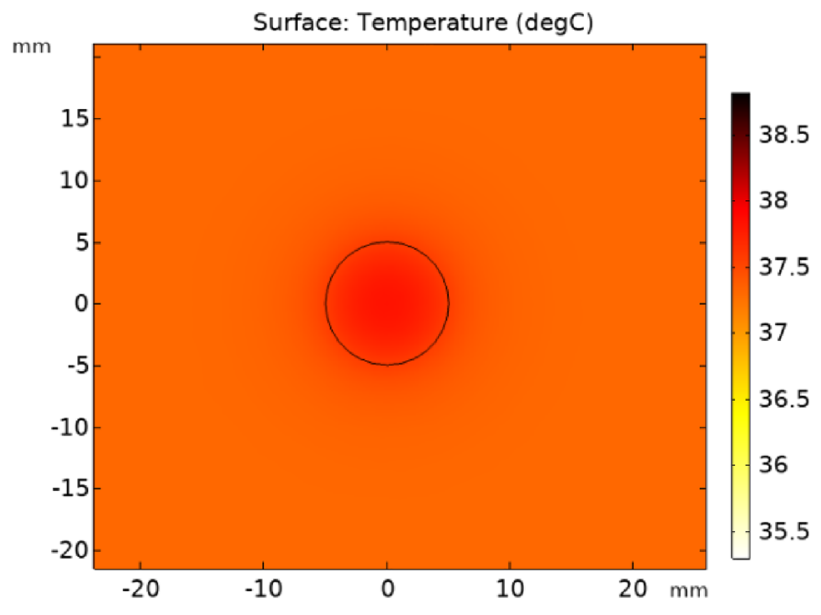

(c)

Fig. 4 Magnified visuals of tumor temperature distribution for three different diameters; a $20 \mathrm{~mm}, \mathbf{b} 15 \mathrm{~mm}, \mathbf{c} 10 \mathrm{~mm}$ 


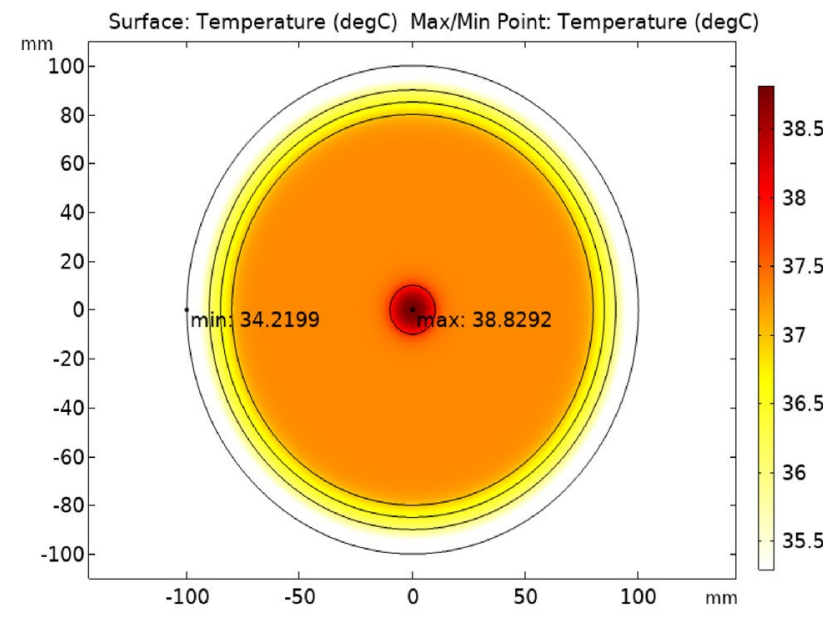

(a)

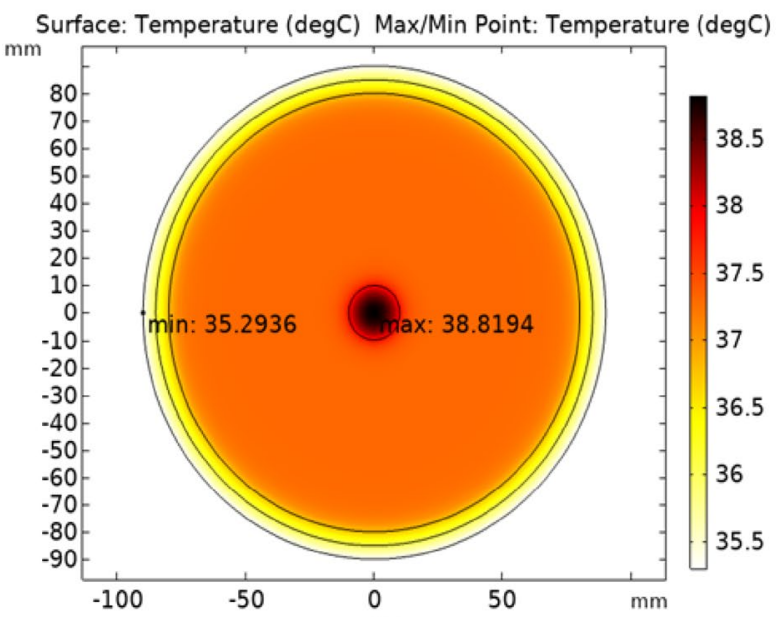

(b)

Fig. 5 Temperature distribution along a tumor with diameter of $20 \mathrm{~mm}$ and the layers of the head (GM-CSF-skull); a with scalp (of thickness of $11 \mathrm{~mm}$ ), $\mathbf{b}$ without scalp

distribution using finite difference method whereas in the current study, the finite element method was conducted for the solution of the Pennes bio-heat transfer equation. Noting that the thermo-physical properties of the tissues are also presented in Table 1.

\subsection{Tumor temperature distribution: effects of diameter}

Figure 3 indicates the effects of the tumor size on the temperature distribution for three different tumor diameters, namely, 10, 15, and $20 \mathrm{~mm}$. Due to this figure, it can be seen that the center of the cancerous tumor has higher temperature than its surrounding normal tissue (about $3^{\circ} \mathrm{C}$ ). Moreover, the maximum temperature at the center of the tumor is increased with increasing the tumor diameter. For the sake of a better visual understanding, results for the tumor temperature fields are also represented in Fig. 4 with magnification.

In present study, in order to simplify the problem solving process and reducing the computational effort, some assumptions have been made. From those which is very important here and have been taken under consideration, is the convective boundary condition between the skull and the air. Basically, as a matter of fact, this condition should be applied at the scalp/air interface. However, a simple simulation of the layers of the head, addressed in the validation section, may allow one to model the scalp layer by using the thermo-physical properties mentioned by Ma et al. [12]. Based on this ground, the results of the temperature distribution are compared with those obtained from the simulation without considering the scalp (Fig. 5). It can be observed from the figure that, due to a very small thickness of the scalp (3-11 $\mathrm{mm}$ ) [26] in relative comparison with the larger size of the head, the temperature values at the center of the tumor for both of the models are extremely close (absolute difference is lower than $0.025 \%$ ) (Fig. 5). Therefore, the effect of the scalp on the heat transfer process can be ignored. Here, the scalp is modeled considering the maximum thickness equal to $11 \mathrm{~mm}$ ).

\subsection{Temperature distribution in tumor and healthy tissues (without hyperthermia)}

Having a geometrically-accurate representation of the vital body tissues, and using the right boundary conditions are established as two major basis in obtaining the temperature distribution in the brain and tumor tissues via the numerical simulation of the bio-heat transfer analysis. In the present study, the thermal characteristics of a simplistic model of the head consists of three spheres representing the skull, the cerebral spinal fluid (CSF), and the gray matter (GM), as well as a spherical tumor at the center of the model, are examined utilizing the finite element method. For this purpose, a realistic thermal simulation was carried out for the human head layers considering the modelled tumor with the volumetric size of $5990 \mathrm{~mm}^{3}$. Figure 6 shows the exact location of the maximum temperature in the tumor for different cross sections. As one may be expected, the maximum values of temperature occurs at nearly center of each cross section while drops to its minimum at the vicinity 


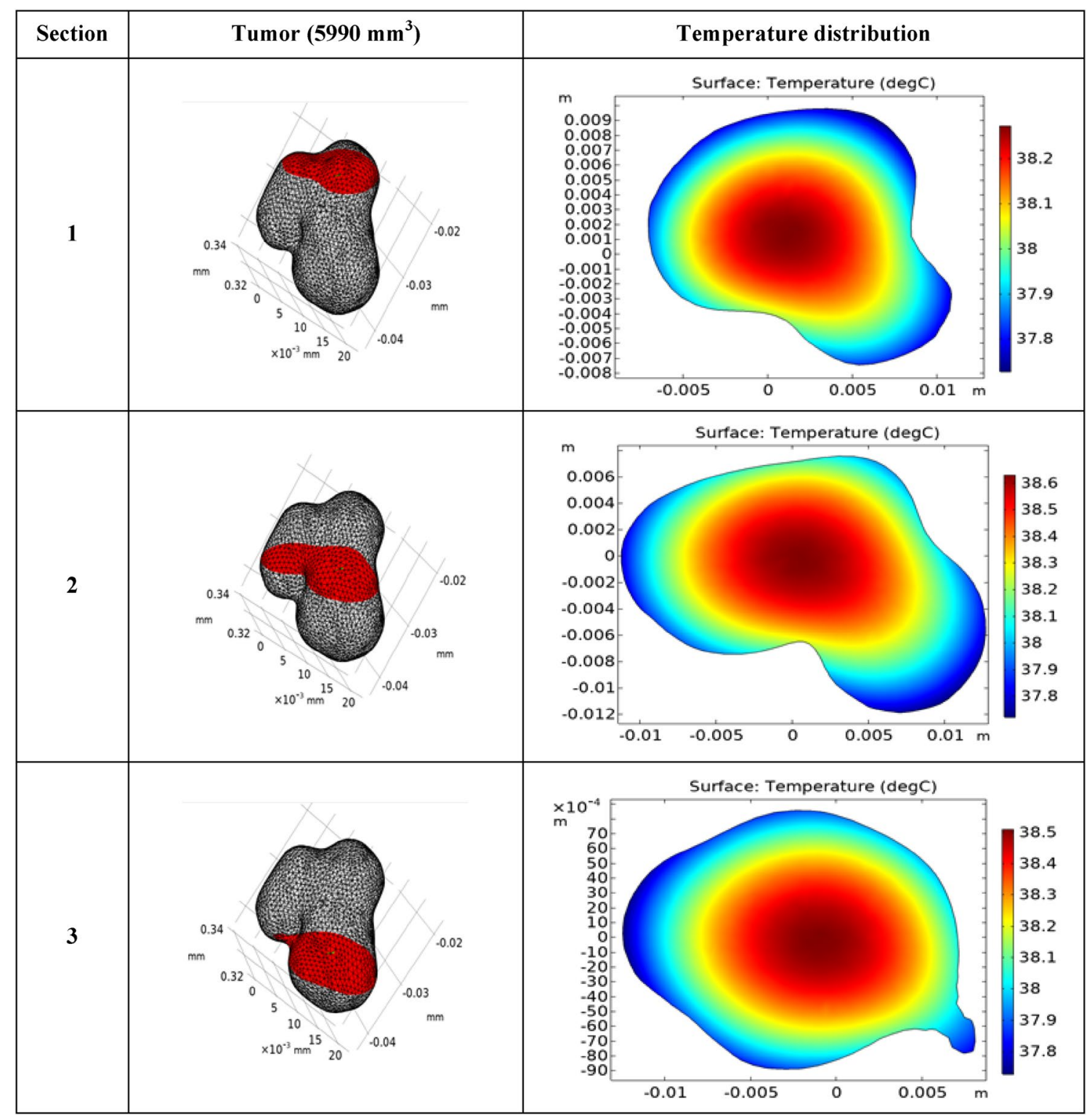

Fig. 6 Temperature distribution in a $5990 \mathrm{~mm}^{3}$ tumor for the three sections
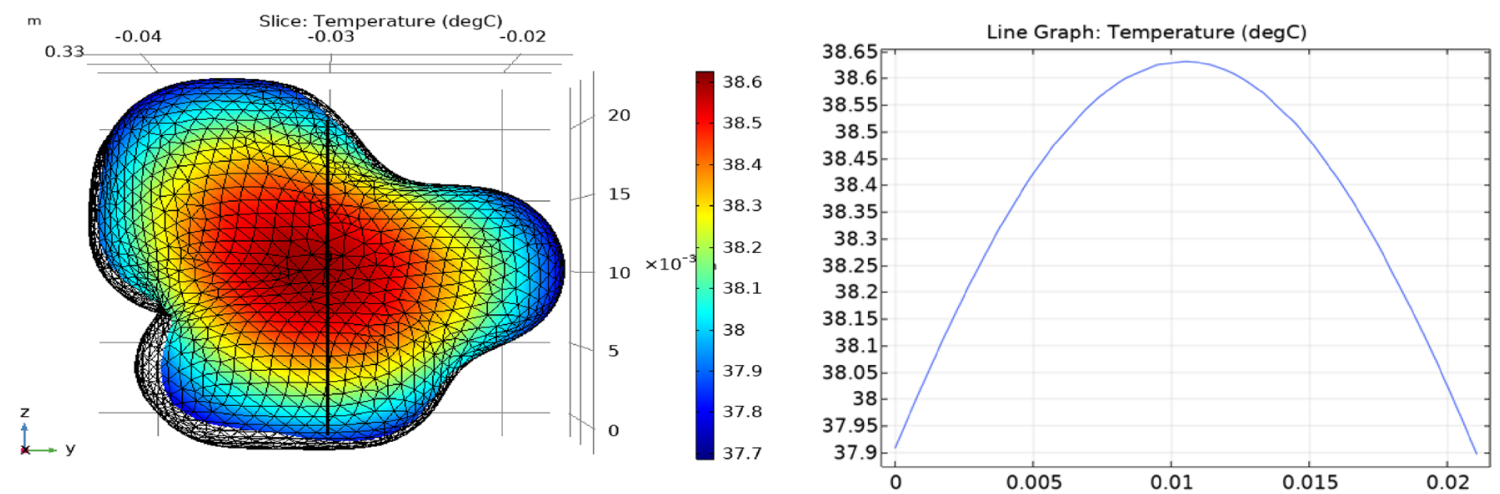

Fig. 7 Temperature profile at the plane passing through the tumor center 
Table 2 Temperature maxima and minima in the tumor and head layers

\begin{tabular}{lll}
\hline Head & $\begin{array}{l}\text { Max. temperature } \\
\left({ }^{\circ} \mathrm{C}\right)\end{array}$ & $\begin{array}{l}\text { Min. tem- } \\
\text { perature } \\
\left({ }^{\circ} \mathrm{C}\right)\end{array}$ \\
\hline Tumor $\left(5990 \mathrm{~mm}^{3}\right)$ & 38.64 & 37.69 \\
White matter $(\mathrm{WM})$ & 38.36 & 36.18 \\
Gray matter (GM) & 37.7 & 34.83 \\
Cerebrospinal fluid (CSF) & 37.32 & 33.02 \\
Skull & 37.16 & 28.18 \\
\hline
\end{tabular}

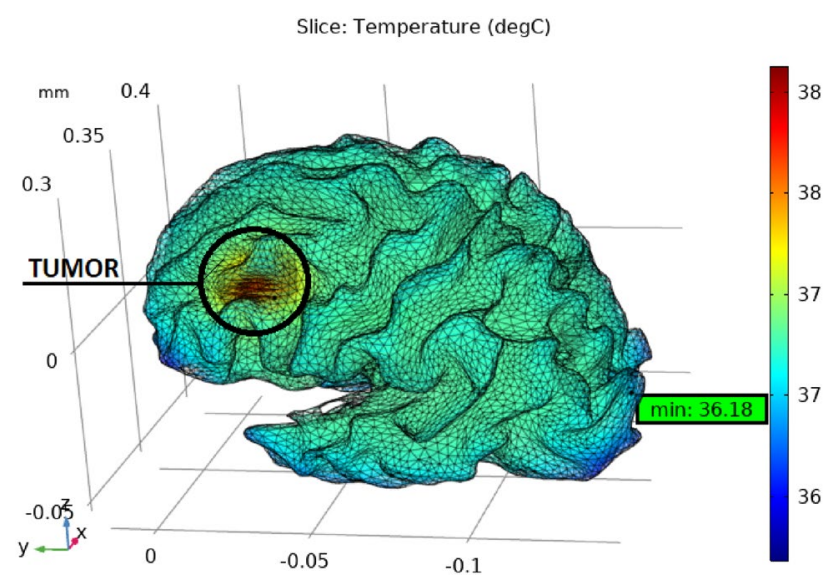

Fig. 8 Temperature distribution in tumor $\left(5990 \mathrm{~mm}^{3}\right)$ and the WM (white matter)

Surface: Temperature (degC) Max/Min Point: Temperature (degC)

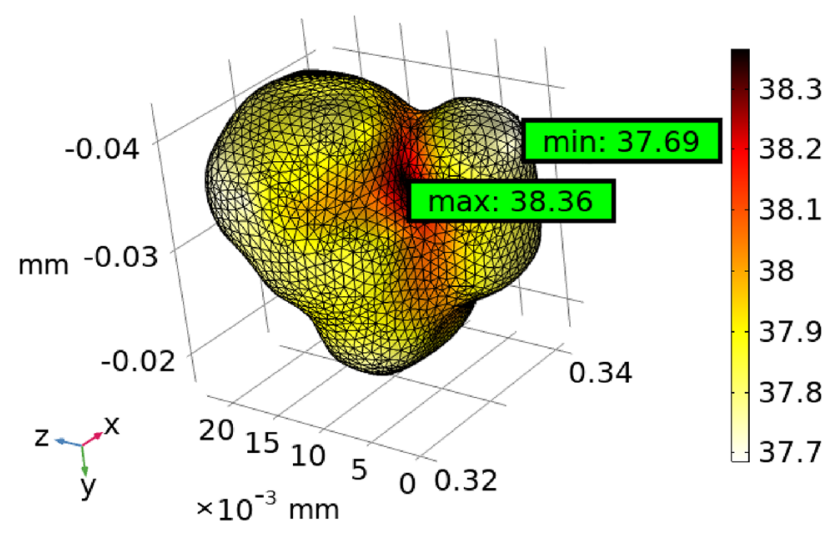

Fig. 9 Temperature distribution over the tumor surface

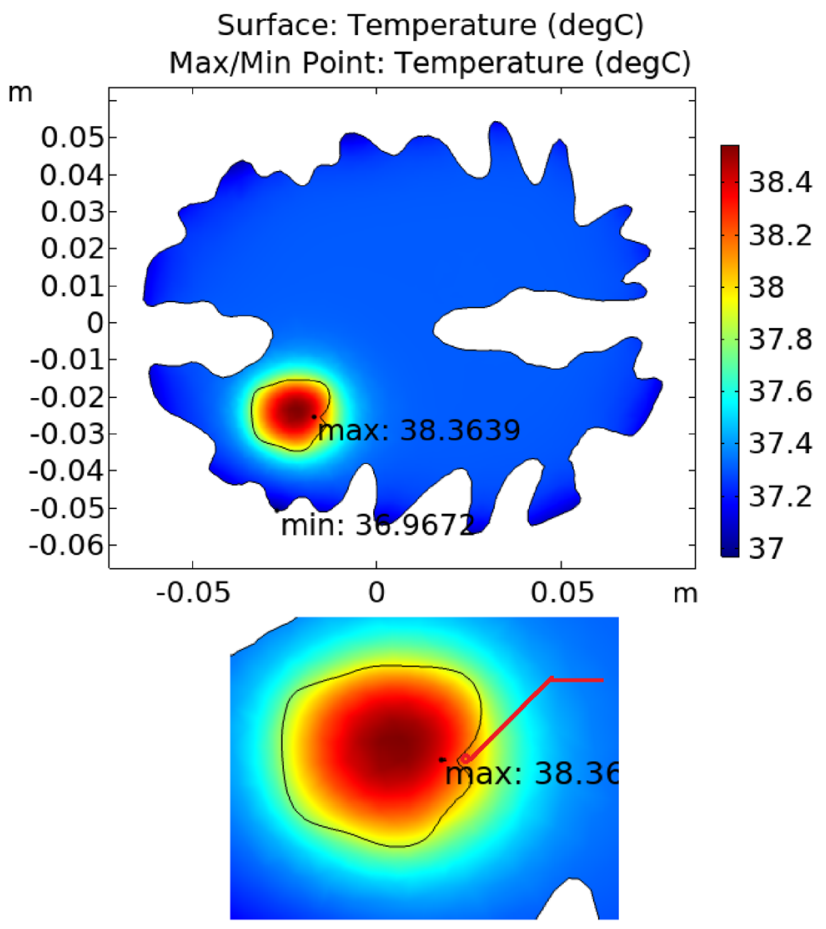

Fig. 10 Temperature distribution over WM (white matter) and the tumor on the cross-section passing through the surface with maximum tumor temperature

of the tumor surface. It can also be noted that the maximum tumor temperature is marked on Sect. 2 (Fig. 6). As far as the temperature profile across the tumor central plane, Fig. 7 demonstrates more clear representation of the temperature profile in the line passing through the center of tumor.

It should be noted that in current study, the tumor is located inside WM, while the other three layers (GM, CSF, and skull) are considered to enable a realistic representation of the human head. The absolute values of temperature, i.e., minima and minima, throughout the tumor and its surrounding tissues are tabulated in Table 2.

Basically, regulating the brain temperature within the permissible limits is a highly sensitive process while can affects the brain tumors. So, having a proper temperature range at each layer of the head can be really effective for development of the safe clinical treatments. The characteristics of the temperature fields for the tumor and the White Matter (WM) are numerically investigated which are presented in Figs. 8, 9, 10, respectively. Figure 8 shows the temperature distribution in the WM and the tumor. 


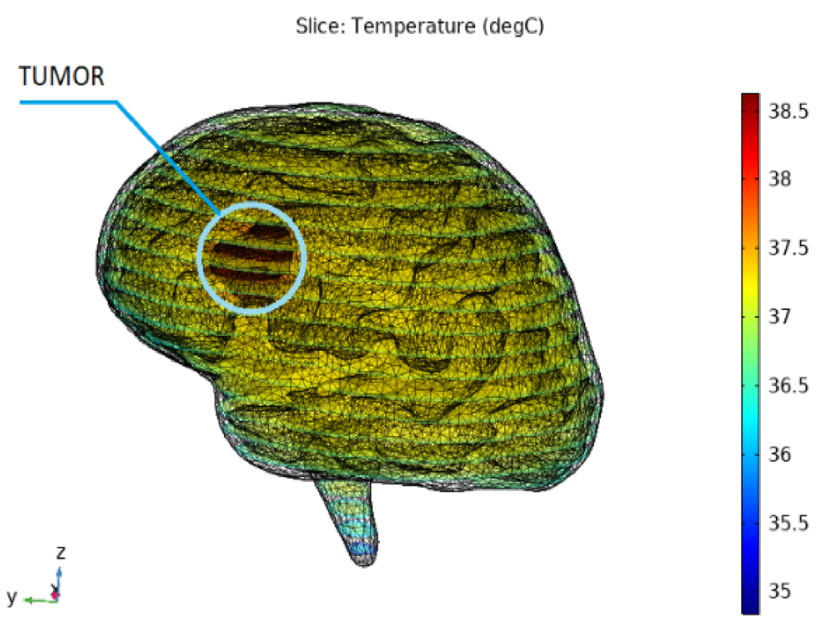

(a)

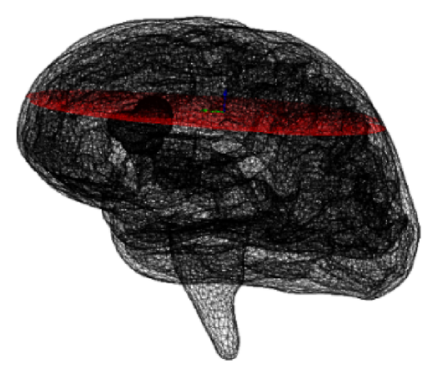

(b)

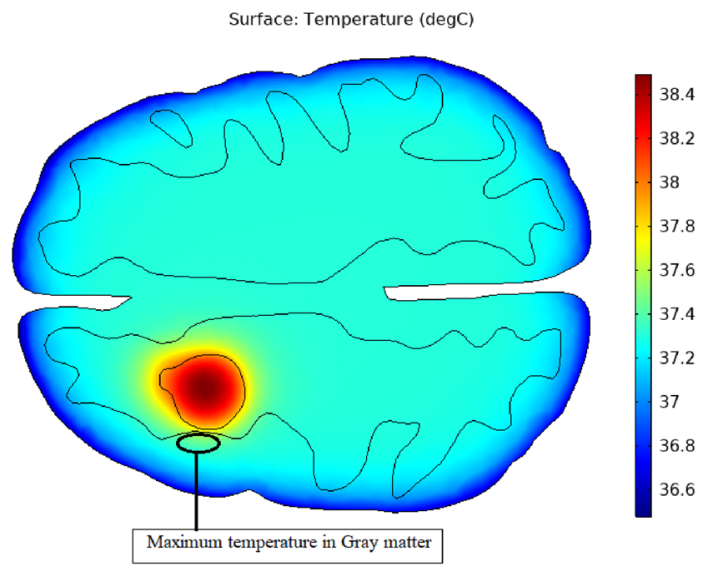

(c)

Fig. 11 a Temperature distribution in WM (white matter)-GM (gray matter) layers and the tumor; $\mathbf{b}$ the cross section passing through the maximum temperature point of GM; c temperature distribution and the hot-spot on the cross section passing through the maximum temperature point of GM
The minimum WM temperature was found to be equal to $36.18^{\circ} \mathrm{C}$ (Table 2). Figure 9 illustrates the temperature distribution over the tumor surface. Accordingly, the maximum temperature of the WM is found to be equal to $38.36{ }^{\circ} \mathrm{C}$, which is marked in Fig. 10 , at the plane passing through a point with maximum temperature.

Figure 11a shows the temperature distribution over the brain matter (WM and GM) and the tumor. As it is evident, the maximum temperature of the head corresponds to the tumor whereas the minimum temperature was obtained as $34.83^{\circ} \mathrm{C}$. Figure $11 \mathrm{~b}$ indicates the geometry and the cross-sectional plane passing through the maximum temperature point of the GM. This plane and its respective hot-spot are also presented in Fig. 11c. The maximum value for the temperature is calculated as $37.7^{\circ} \mathrm{C}$.

Figure 12a shows the temperature distribution over the layers of WM, GM, CSF, and the tumor. It can be observed from the figure that the minimum CSF temperature is equal to $33.02{ }^{\circ} \mathrm{C}$. For the sake of a better illustration of the temperature distribution, Fig. $12 \mathrm{~b}$ depicts the temperature field on the 2D-plane passing through the center of the tumor. The three-dimensional (3D) meshing frame-work for the CSF and the mentioned crosssectional plane are also presented in Fig. 12c. Figure 12d exhibits the temperature distribution in the CSF tissue.

Figure 13 shows the thermal analysis of a brain tumor in an MRI image belongs to the study of Bousselham et al. [17]. The size of the tumor is about $27,400 \mathrm{~mm}^{3}$. They reported the peak temperature at the center of the tumor as $40.03^{\circ} \mathrm{C}$. Due to Table 2 , the maximum temperature difference between the present results and the work of Bousselham et al., at the center of the tumor is about $1.39^{\circ} \mathrm{C}$

Figure 14a shows the temperature distribution over the entire head comprised of WM, GM, CSF, skull, and the tumor. The minimum temperature is found to be about $28.18{ }^{\circ} \mathrm{C}$ which occurs at the outer surface of the skull. A cross-sectional plane runs through all layers of the head layers, as well as the tumor which graphically illustrates the temperature distribution at the 2D plane (Fig. 14b, c).

Figure 15a indicates the temperature field at the crosssectional plane passing through all of the head layers. Figure $15 \mathrm{~b}$ shows the temperature profile in the head model for two different cases: without the tumor, and in the presence of the tumor. Evidently, it can be observed from the profile that the minima at the start and at the 


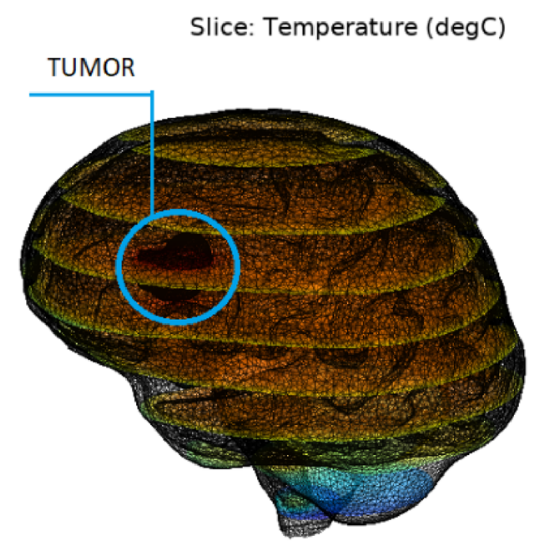

(a)

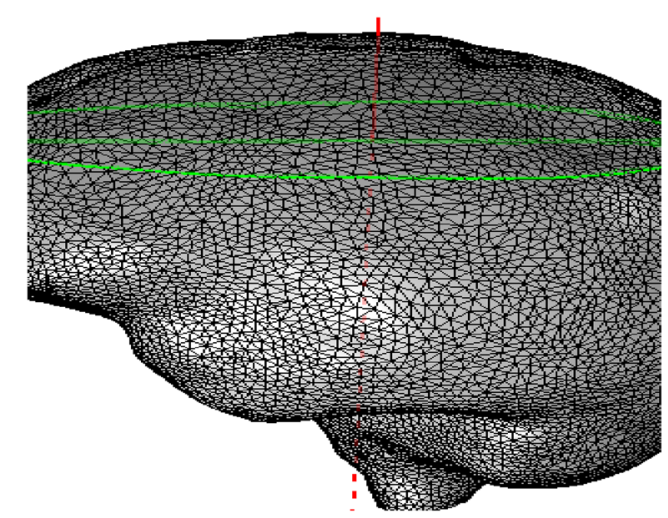

(c)

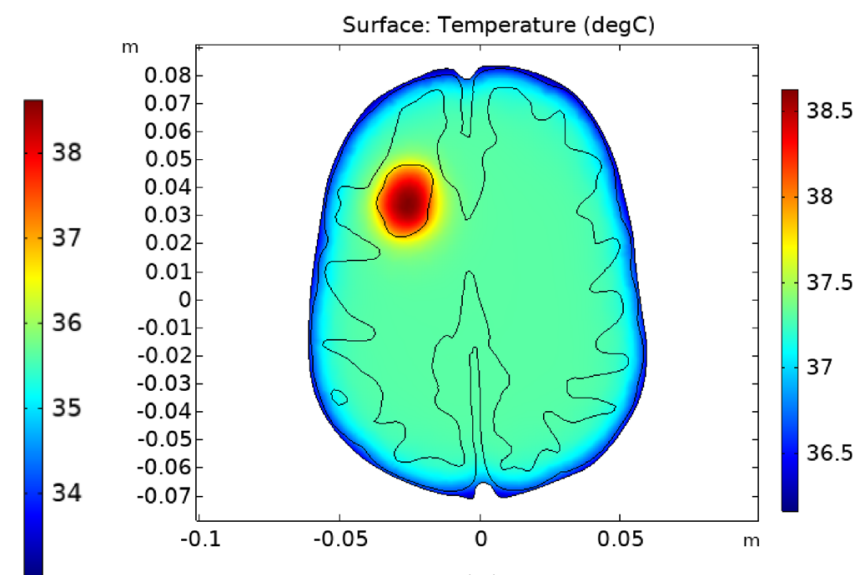

(b)

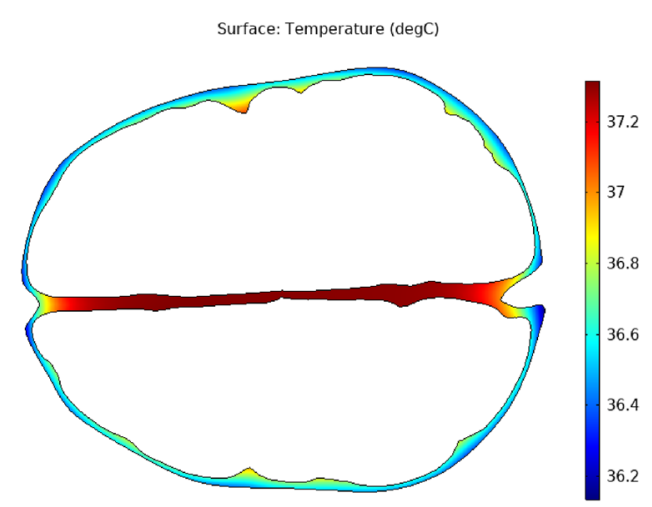

(d)

Fig. 12 a Temperature distribution over WM (white matter), GM (gray matter), CSF (cerebro spinal fluid), and tumor; b temperature distribution on the cross section passing through the center of

end of the line correspond to the skull, while the peak is located at the center of the tumor (green line). Meanwhile, for the case of a brain without the tumor, the peak temperature is located on the brain matter (blue line).

\subsection{Tumor temperature distribution: effects of tumor blood perfusion and metabolism (with hyperthermia)}

One of the prominent approaches to eliminate the cancerous cells is thermal therapy. In this method, a temperature range of $40-46{ }^{\circ} \mathrm{C}$ is required for the elimination of the tumor [10]. Temperature control is a critical part of the thermal simulation of human body tissues for eliminating cancerous tumors. In fact, normal tissue

is sensitive to the temperature rising. Therefore, it is essential that the temperature is raised up to $41-45^{\circ} \mathrm{C}$ in the cancerous tissue, while it must not exceed $41^{\circ} \mathrm{C}$ in the healthy tissue [27]. In this section, the effects of two thermo-physical parameters, namely, the blood perfusion rate, and the tumor metabolism, on the temperature of the tumor are investigated. Different values for the two mentioned parameters are considered which presented in Table 3. According to the results of the study conducted by Bousselham et al. [17] on an $11,600 \mathrm{~mm}^{3}$ tumor, with $w_{b}=0.0016(\mathrm{ml} /(\mathrm{ml} . \mathrm{s}))$, the maximum temperature of the tumor obtained as $39.36^{\circ} \mathrm{C}$; however, for $w_{b}=0.001(\mathrm{ml} /(\mathrm{ml} . \mathrm{s}))$ there is a rise of $0.17^{\circ} \mathrm{C}$ in temperature at the center of the tumor. If, in present study, the same values for blood perfusion rate be considered for 

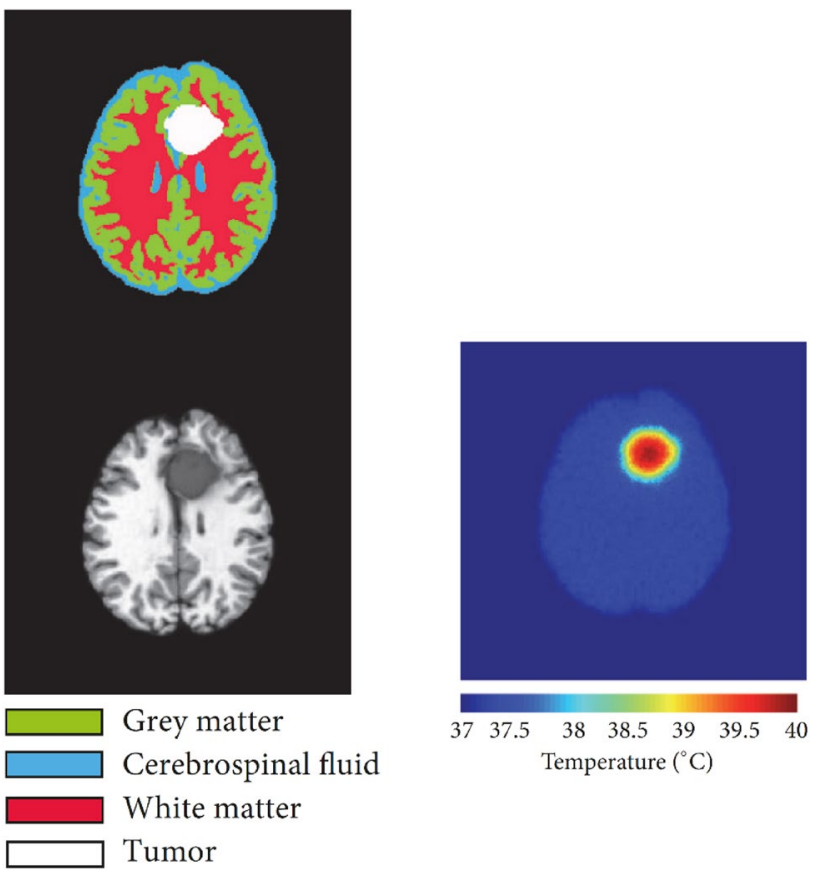

Fig. 13 Thermal analysis of brain tumor in MRI image segmentation [17]

the tumor (the size of the tumor in the present work is half of the volume of the tumor mentioned in the work of Bousselham et al.), the maximum temperature will be increased from 38.35 to $38.52^{\circ} \mathrm{C}$. It should be noted that the difference between the maximum temperatures in the two studies is about $1{ }^{\circ} \mathrm{C}$. Based on the initial results, if $w_{b}=0.0005(\mathrm{ml} /(\mathrm{ml} . \mathrm{s}))$ be considered for the tumor, the temperature at the center of the tumor will be $38.64{ }^{\circ} \mathrm{C}$.

Figure 16 shows the effect of three different blood perfusion rates on the temperature profile along the line passing through the center of the tumor. The maximum temperatures at the center of tumors show no remarkable differences for the three illustrated plots implying that decreasing the blood perfusion rate does not increase the temperature of the tumor, significantly. Hence, it does not provide the desired condition of hyperthermia.

Figure 17 indicates the tumor temperature along a line passing through the center of the tumor for increasing values of the tumor metabolism, $Q_{m e t}$, while the blood perfusion rate is constant at $w_{b}=0.001(\mathrm{ml} /(\mathrm{ml} . \mathrm{s}))$. As the figure shows, the ideal temperature for tumor elimination can be obtained when the tumor metabolism is increased
Table 3 Different values for blood perfusion rate $\left(w_{b}\right)$, and metabolic heat generation $\left(Q_{m e t}\right)$

\begin{tabular}{ll}
\hline Parameter & Value \\
\hline$w_{b}(\mathrm{ml} /(\mathrm{ml} . \mathrm{s}))$ & 0.0005 \\
& 0.0016 \\
& 0.001 \\
$Q_{\text {met }}\left(\mathrm{W} / \mathrm{m}^{3}\right)$ & $25 \times 10^{3}$ \\
& $30 \times 10^{3}$ \\
& $60 \times 10^{3}$ \\
& $90 \times 10^{3}$ \\
& $125 \times 10^{3}$ \\
\hline
\end{tabular}

five times (equal to $125 \times 10^{3} \mathrm{~W} / \mathrm{m}^{3}$ ) than the normal rate $\left(Q_{m e t}=25,000 \mathrm{~W} / \mathrm{m}^{3}\right)$ (Fig. 18). As it is shown in Fig. 18, the maximum temperature in the healthy tissue obtained as $41.37^{\circ} \mathrm{C}$. In fact, the obtained numerical results in Fig. 18 shows that when the amount of the heat produces inside the tumor reaches $125 \times 10^{3}\left(\mathrm{~W} / \mathrm{m}^{3}\right)$, the temperature control creates to provide hyperthermia condition without causing damage through rising temperature in the healthy tissue.

Figure 19 illustrates the temperature variations along a line passing through all the layers of the head for two different values of tumor metabolism, namely, $Q_{m e t}=25 \times 10^{3}\left(\mathrm{~W} / \mathrm{m}^{3}\right)$, and $Q_{m e t}=125 \times 10^{3}(\mathrm{~W} /$ $\left.\mathrm{m}^{3}\right)$. Due to this figure, when the tumor metabolism increases five times, the temperature distribution does not varies substantially in all of the head layers but only in few regions including a small portion of white matter (WM). This means that the rest of the layers (Gray Matter, Cerebrospinal Fluid and Skull) are not affected. In other words, the major temperature difference between the two plots occurs in the tumor and in a small region of he WM adjacent to the tumor.

Generally, there are different techniques for thermal therapy. Magnetic fluid hyperthermia (MFH) is a common modern method for the elimination of the cancerous tumor. In this method, by injecting a magnetic fluid into the tumor and then applying an AC magnetic field to the area, the Magnetic Nanoparticles (MNPs) act as a heat source inside the tumor, and consequently, the temperature enhances inside the tumor. Figure 20 indicates that $Q_{\text {met }}$ equal to $125 \times 10^{3} \mathrm{~W} / \mathrm{m}^{3}$ provides the great effects on the tumor temperature in hyperthermia implementation, if one employs the method of MFH in order to increase the temperature in the tumor considering $125 \times 10^{3} \mathrm{~W} / \mathrm{m}^{3}$ heat produced by nanoparticles. The temperature variations along the line 
Fig. 14 a Temperature distribution over the entire layers of head; b, c Temperature distribution on the cross-sectional plane passing through the head layers and the tumor

passing through the center of the tumor can be seen in Fig. 20, considering the the heat of metabolism and the MFH technique.

Figure 21 shows that without changing the tumor metabolism $\left(Q_{m e t}=25,000 \mathrm{~W} / \mathrm{m}^{3}\right)$, the produced heat of $125 \times 10^{3} \mathrm{~W} / \mathrm{m}^{3}$ by nanoparticles inside the tumor may cause that some parts of the normal tissue reach to a temperature equal to $42.52^{\circ} \mathrm{C}$. It seems that this amount of temperature may damage the healthy tissue of the brain. In fact, using the MFH method, the total volumetric heat source in tumor becomes equals to $150 \times 10^{3} \mathrm{~W} / \mathrm{m}^{3}$ (the sum of tumor metabolism and the heat produced by nanoparticles). Therefore, in order to supply the heat required for tumor ablation and prevent the damage to the normal tissue, the total heat source of $125 \times 10^{3} \mathrm{~W} / \mathrm{m}^{3}$ provide the desired conditions of hyperthermia. Hence, the heat produced by the nanoparticles for a tumor with the size of $5990 \mathrm{~mm}^{3}$ is calculated and found to be equal to $10^{5} \mathrm{~W} / \mathrm{m}^{3}$.

\section{Conclusion}

As a matter of fact, it is difficult to present an analytical solution for complex shapes like human tissue. Therefore, different numerical methods (finite element, finite volume and finite difference) may be used for such complicated cases. In present study, the major aim was to present a realistic geometry of the main layers of the head (Skull, CSF, Gray Matter and White Matter) to achieve a thermal simulation of the tumor using the finite element scheme. The Pennes bio-heat transfer equation was utilized to conduct a thermal analysis of the layers of the head and the tumor. The obtained numerical results related to the temperature of the tumor and the layers of the head were presented in different plots and figures. Subsequently, the conditions of thermal therapy and controlling the temperature were examined. Finally, the elimination of the tumor were investigated via changes in two parameters, i.e., perfusion and metabolism rate in the tumor. A summary of the results is presented as below:

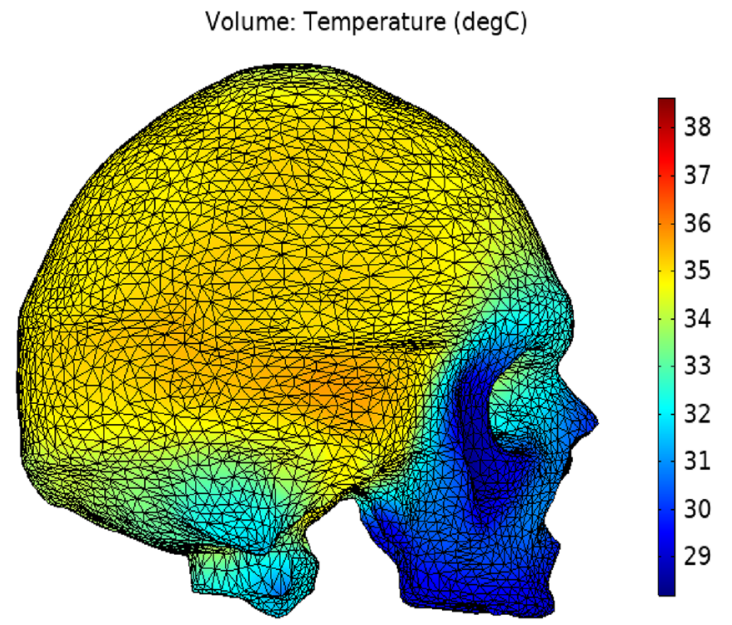

(a)

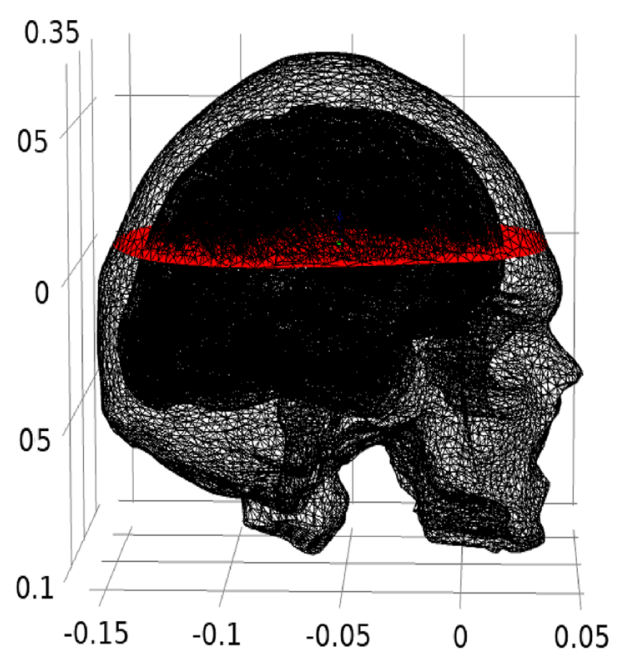

(b)

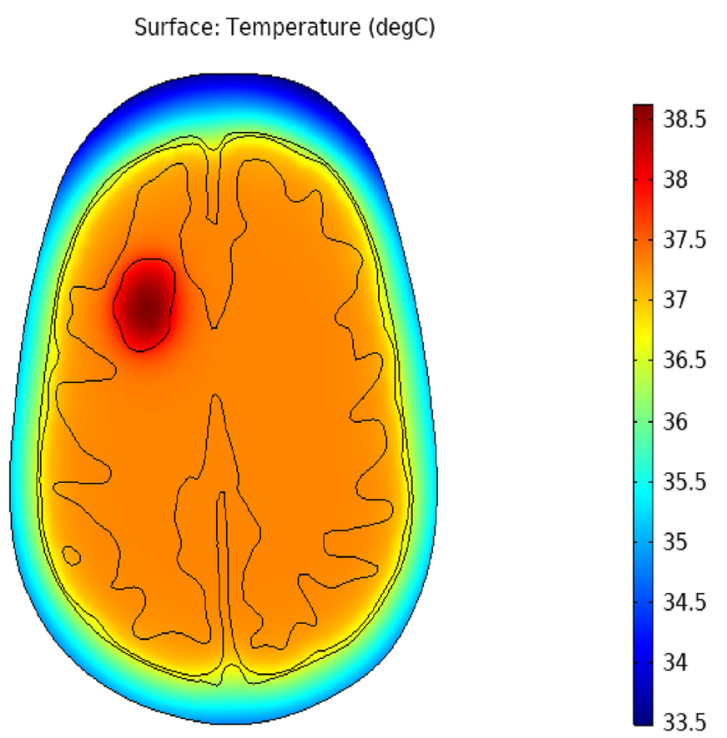

(c) 


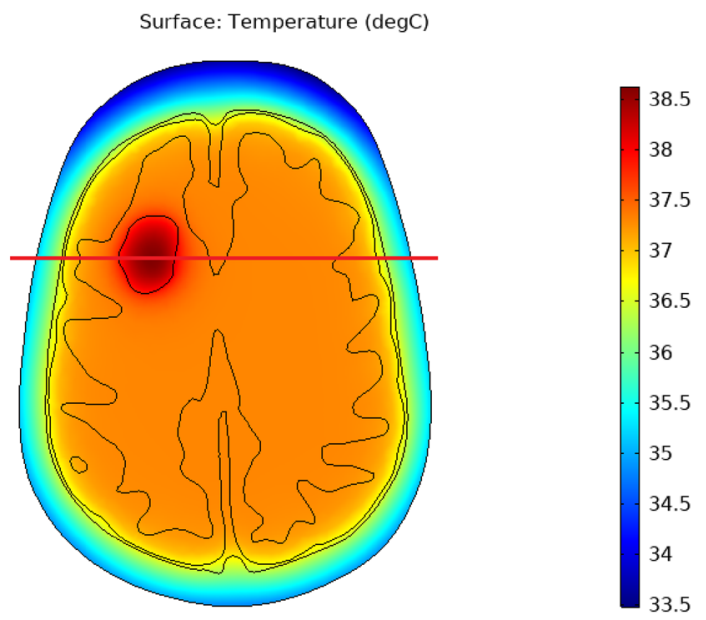

(a)

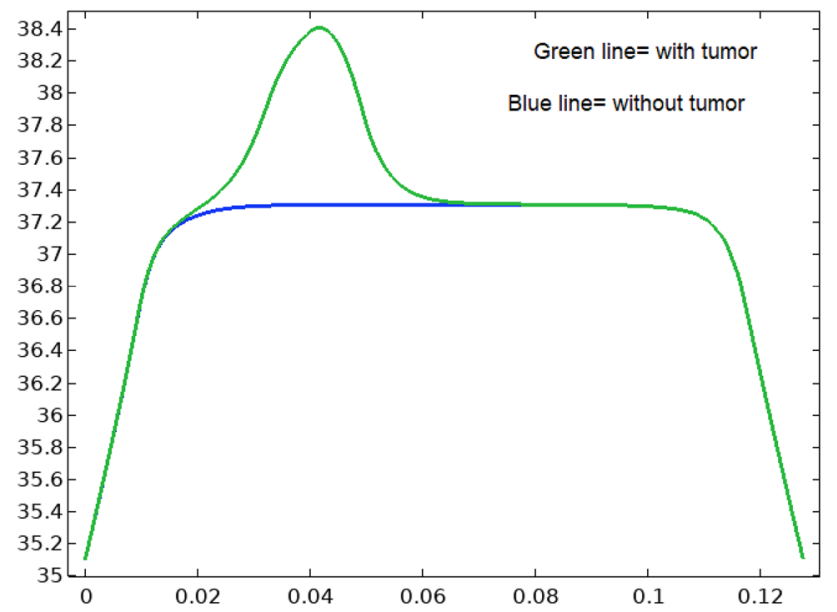

(b)

Fig. 15 a A line through the tumor center and all of the head layers; $\mathbf{b}$ Temperature distribution in the head model with tumor and without tumor

1. The change observed in the slope of the temperature plot for the different layers of the head is a result of their different thermo-physical properties. The horizontal line in the whole head temperature distribution plot, showing $37.3^{\circ} \mathrm{C}$, is related to the white matter and gray matter layers. This indicates the fact that the temperature equals $37.3^{\circ} \mathrm{C}$ on average, in most parts of the gray matter and white matter. Furthermore, the maximum temperature on the plot belongs to the tumor due to the significant difference in the rate of metabolism in this area compared to the rest of the head.

2. Regulating brain temperature is very effective in brain tumors, so having temperature range in each layer of the head, can be effective for development of safe clinical treatments. Table 2 showed the temperature minima and maxima in each layer of head. In fact, by thermally simulating the layers of the head, the temperature of any point of the layers (WM-GM-CSFSKULL) can be available.

3. If only one decreases the blood perfusion rate, the tumor temperature does not increase, significantly. Therefore, it does not provide the desired condition of hyperthermia.

4. Changing the values of the tumor metabolism affects its temperature significantly; consequently, in present study, the necessary temperature for tumor elimination was achieved in the whole of the tumor by increasing the metabolism to 5 times of its original value. Although, the shaped of tumor was asymmetrically, this amount of heat allowed for temperature control, all over the tumor, to prevent damage to the surrounding normal tissue.

5. If magnetic fluid hyperthermia method being used, the necessary heat is 4 times the tumor metabolism value, which is equivalent to $10^{5} \mathrm{~W} / \mathrm{m}^{3}$. This value is sufficient for hyperthermia conditions, and damage to the surrounding healthy tissue is prevented.

6. The asymmetric shape of the tumor is one of the main reasons why temperature control is essential to the process of hyperthermia. Therefore, it is crucial to pay attention to how fluid is injected to the tumor, in magnetic fluid hyperthermia (MFH).

7. The value of metabolism parameter in a cancerous tissue is a good criterion for estimating the amount of heat required for tumor destruction in MFH method. Changing this parameter in a thermal simulation allows us to estimate the heat required for the elimination of the tumor, before injecting nanoparticles to the cancerous tissue and creating the appropriate magnetic field. 
Fig. 16 The tumor temperature distribution along the line passing through the center of tumor, considering different values of $w_{b}$
Fig. 17 The tumor temperature distribution on the path passing through the center of tumor for different values of $Q_{\text {met }}$
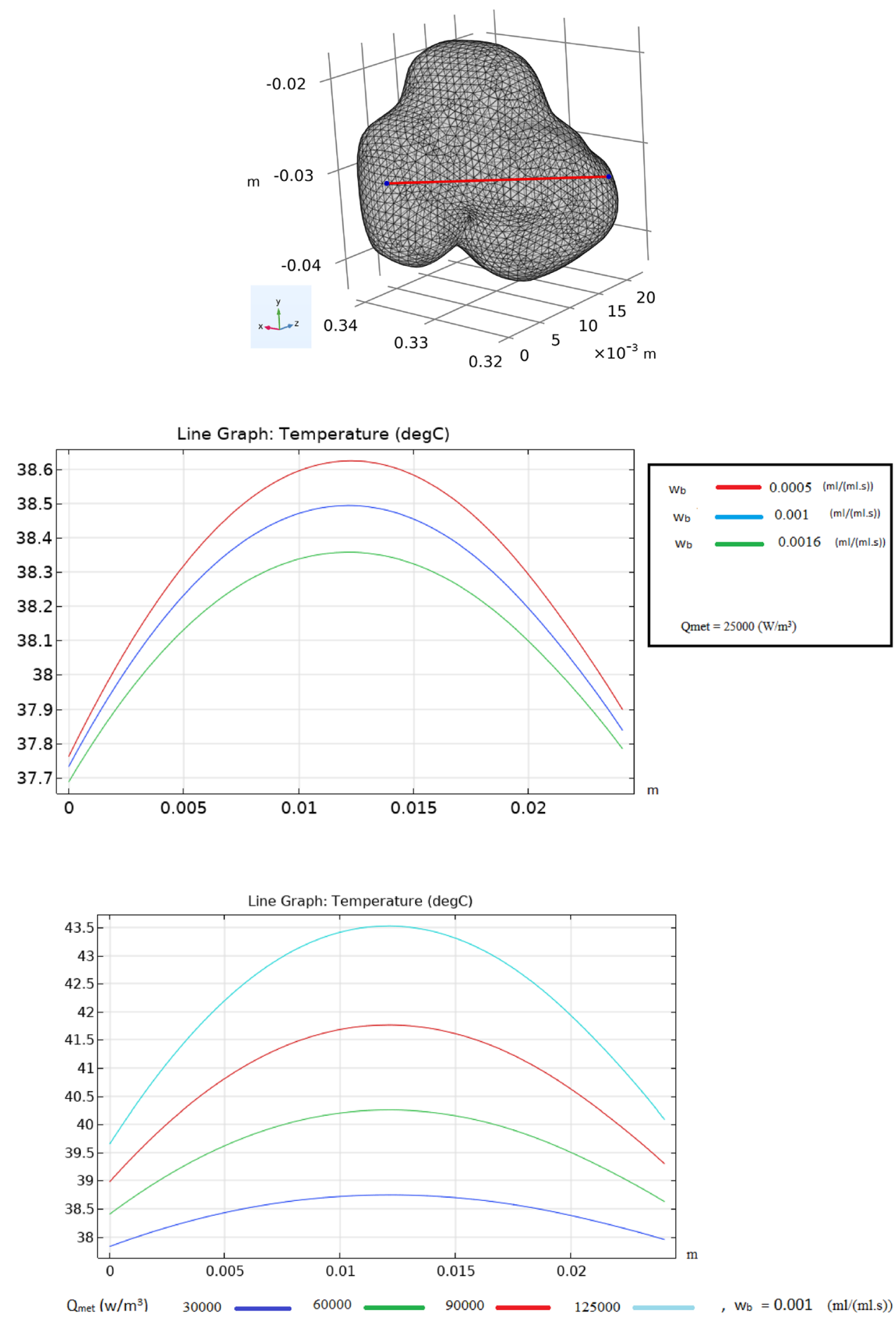


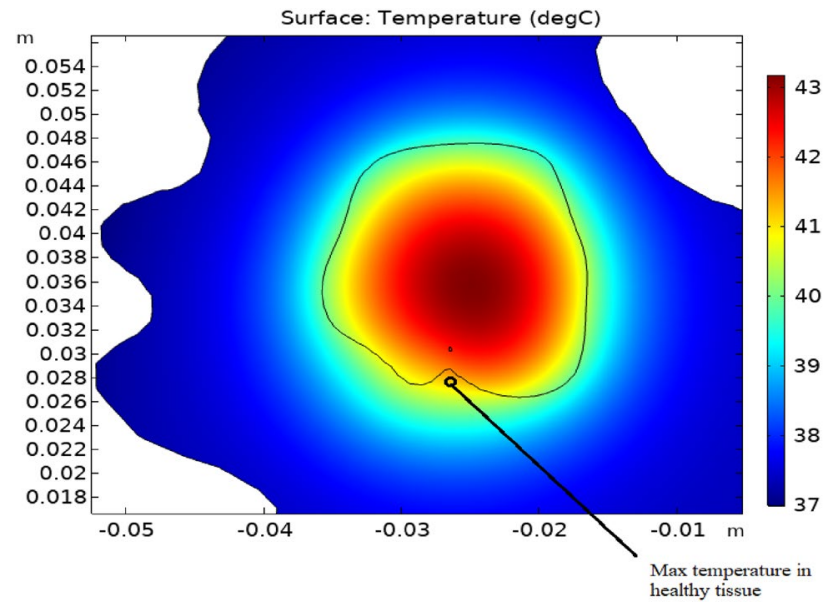

Fig. 18 The temperature distribution in the tumor and the surrounding healthy tissue (white matter) on the cross section passing the maximum temperature of WM for $Q_{m e t}=125 \times 10^{3}\left(\mathrm{~W} / \mathrm{m}^{3}\right)$ and $w_{b}=0.001(\mathrm{ml} /(\mathrm{ml} . \mathrm{s}))$

Fig. 19 Comparing the temperature distribution across all the layers of the head, when tumor metabolism is increased 5 times and blood perfusion rate remains constant at $w_{b}=0.001(\mathrm{ml} /(\mathrm{ml} . \mathrm{s}))$

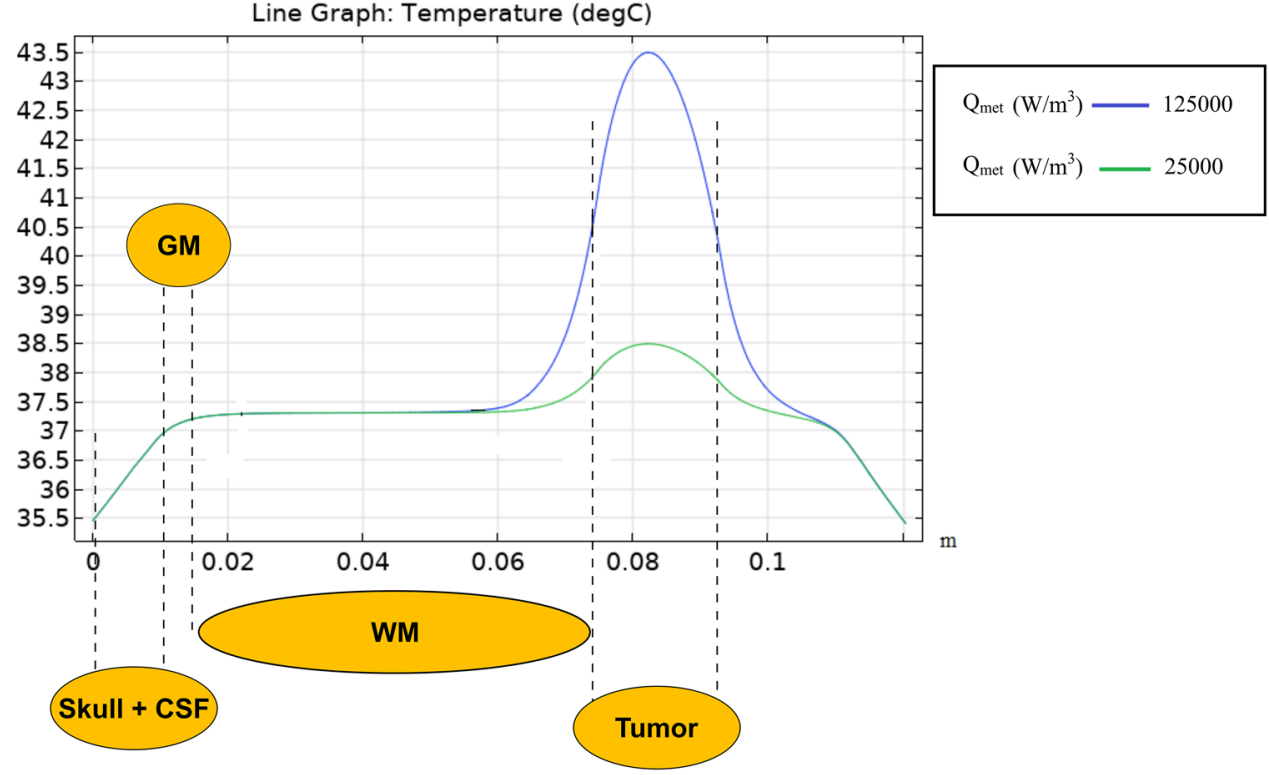

Fig. 20 Temperature distribution of the tumor for constant blood perfusion rate of $w_{b}=0.001(\mathrm{ml} /(\mathrm{ml} . \mathrm{s}))$, under conditions of hyperthermia for two different techniques: heat produced by nanoparticles $Q_{M N P}=125 \times 10^{3} \mathrm{~W} / \mathrm{m}^{3}$ (green line); heat produced by increasing the tumor metabolism $Q_{\text {met }}=125 \times 10^{3} \mathrm{~W} / \mathrm{m}^{3}$ (blue line), along the cross section passing through the center of the tumor

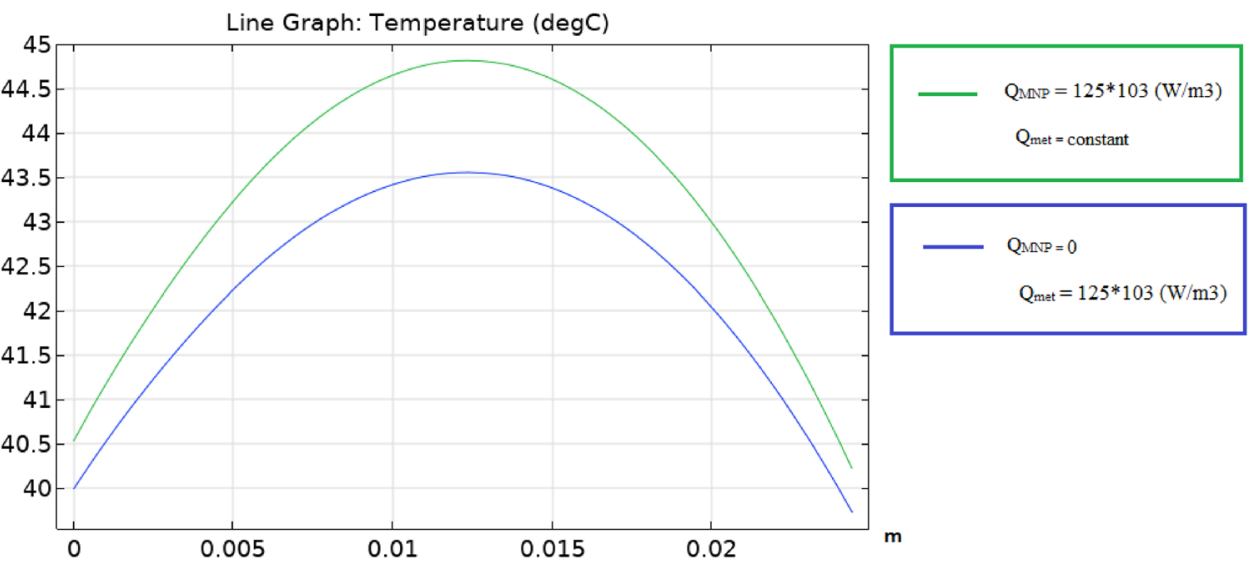

In this research, many assumptions were made to simplify the problem solving process. These simplifications can be neglected in other studies in order to achieve the most optimal and accurate estimation of hyperthermia treatment. In future works, a bio-heat transfer equation more accurate than the Pennes bio-heat transfer equation can be used.

SN Applied Sciences 


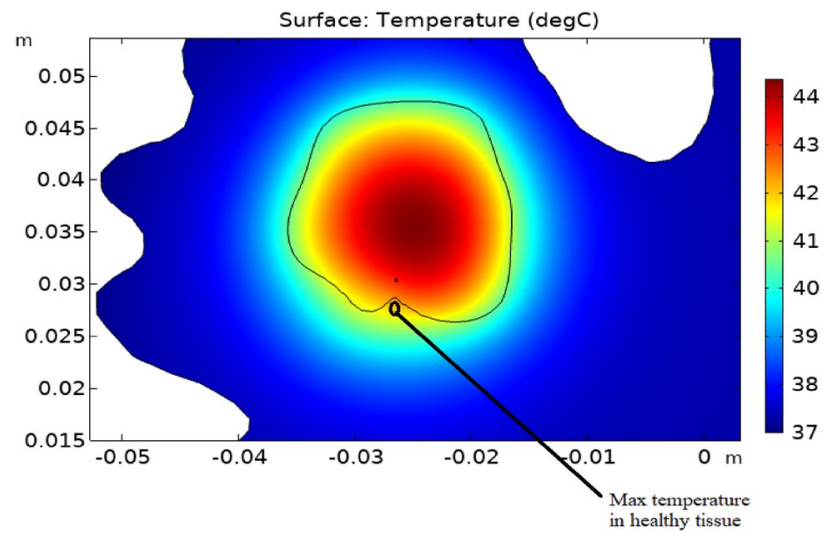

Fig. 21 The temperature distribution in the tumor and the surrounding healthy tissue (white matter) on the cross section passing the maximum temperature of WM for $Q_{M N P}=125 \times 10^{3}\left(\mathrm{~W} / \mathrm{m}^{3}\right)$ without modifying the tumor metabolism while blood perfusion is constant at $w_{b}=0.001(\mathrm{ml} /(\mathrm{ml} . \mathrm{s}))$

\section{Compliance with ethical standards}

Conflict of interest Authors declare that they have no conflict of interest.

Ethical approval This article does not contain any studies with human participants or animals performed by any of the authors. Menelik head mesh model (STL files) was used in this study [20].

Open Access This article is licensed under a Creative Commons Attribution 4.0 International License, which permits use, sharing, adaptation, distribution and reproduction in any medium or format, as long as you give appropriate credit to the original author(s) and the source, provide a link to the Creative Commons licence, and indicate if changes were made. The images or other third party material in this article are included in the article's Creative Commons licence, unless indicated otherwise in a credit line to the material. If material is not included in the article's Creative Commons licence and your intended use is not permitted by statutory regulation or exceeds the permitted use, you will need to obtain permission directly from the copyright holder. To view a copy of this licence, visit http://creativecommons .org/licenses/by/4.0/.

\section{References}

1. Wang H, Wang B, Normoyle KP, Jackson K, Spitler K, Sharrock MF, Miller CM, Best C, Llano D, Rose Du (2014) Brain temperature and its fundamental properties: a review for clinical neuroscientists. Front Neurosci 8:307. https://doi.org/10.3389/fnins.2014.00307

2. Pennes HH (1948) Analysis of tissue and arterial blood temperatures in the resting human forearm. J Appl Physiol 1:93-122. https://doi.org/10.1152/jappl.1948.1.2.93

3. Chen MM, Holmes KR (1980) Microvascular contributions in tissue heat transfer. Ann N Y Acad Sci 335:137-150. https://doi. org/10.1111/j.1749-6632.1980.tb50742.x

4. Jiji LM, Weinbaum S, Lemons DE (1984) Theory and experiment for the effect of vascular microstructure on surface tissue heat transfer-part II: model formulation and solution. J Biomech Eng. https://doi.org/10.1115/1.3138502

5. Weinbaum S, Jiji LM (1985) A new simplified bioheat equation for the effect of blood flow on local average tissue temperature. https://doi.org/10.1115/1.3138533

6. Zolfaghari A, Maerefat M (2011) Bioheat transfer. In: Developments in heat transfer. IntechOpen. https://doi. org/10.5772/22616

7. Dagan Z, Weinbaum S, Jiji LM (1986) Erratum: “Parametric Studies on the Three-Layer Microcirculatory Model for Surface Tissue Energy Exchange"(Journal of Biomechanical Engineering, 1986, 108, pp. 89-96). https://doi.org/10.1115/1.3138585

8. Jayasundar R, Singh VP (2002) In vivo temperature measurements in brain tumors using proton MR spectroscopy. Neurol India 50:436-439 (Corpus ID: 21993420)

9. Bousselham A, Bouattane O, Youssfi M, Raihani A (2018) Brain tumor temperature effect extraction from MRI imaging using bioheat equation. Procedia Comput Sci 127:336-343. https:// doi.org/10.1016/j.procs.2018.01.130

10. Tang Y-D, Flesch RCC, Jin T (2019) Numerical method to evaluate the survival rate of malignant cells considering the distribution of treatment temperature field for magnetic hyperthermia. J Magn Magn Mater 490:165458. https://doi.org/10.1016/j. jmmm.2019.165458

11. Bousselham A, Bouattane O, Youssfi M, Raihani A (2018) 3D brain tumor localization and parameter estimation using thermographic approach on GPU. J Therm Biol 71:52-61. https://doi. org/10.1016/j.jtherbio.2017.10.014

12. Ma W, Liu W, Li M (2016) Analytical heat transfer model for targeted brain hypothermia. Int J Therm Sci 100:66-74. https://doi. org/10.1016/j.ijthermalsci.2015.09.014

13. Majchrzak E, Turchan $\measuredangle$ (2017) Numerical analysis of tissue heating using the bioheat transfer porous model. Comput Assisted Methods Eng Sci 20:123-131

14. Kengne E, Lakhssassi A (2015) Analytico-numerical study of bioheat transfer problems with temperature-dependent perfusion. Eur Phys J Plus 130:1-18. https://doi.org/10.1140/epjp/i2015 -15089-1

15. Hossain S, Mohammadi F (2013) One-dimensional steadystate analysis of bioheat transfer equation: tumour parameters assessment for medical diagnosis application. In: Proceedings 6th international multi-conference on engineering and technological innovation (IMETI 2013), pp 26-30

16. Kohani M, Talebi M, Shafii MB (2011) Modeling and optimizing the temperature distribution around cancerous tissues during magnetic hyperthermia treatment. In: Proceedings of the international conference on modeling, simulation and visualization methods (MSV), 1. The Steering Committee of the World Congress in Computer Science, Computer...

17. Bousselham A, Bouattane O, Youssfi M, Raihani A (2019) Towards reinforced brain tumor segmentation on MRI images based on temperature changes on pathologic area. Int J Biomed Imaging. https://doi.org/10.1155/2019/1758948

18. Shirkavand A, Nazif HR (2019) Numerical study on the effects of blood perfusion and body metabolism on the temperature profile of human forearm in hyperthermia conditions. J Therm Biol 84:339-350. https://doi.org/10.1016/j.jtherbio.2019.07.023

19. Stanković V, Jovanović D, Krstić D, Marković V, Cvetković N (2017) Temperature distribution and specific absorption rate inside a child's head. Int J Heat Mass Transf 104:559-565. https://doi. org/10.1016/j.ijheatmasstransfer.2016.08.094

20. Kibret B, Premaratne M (2018) Menelik head mesh model (STL files). https://doi.org/10.4225/03/5b2c64f668b73

21. Zhang $H$ (2008) Lattice Boltzmann method for solving the bioheat equation. Phys Med Biol 53:N15. https://doi. org/10.1088/0031-9155/53/3/N01 
22. Bagum MN, Shaha A, Ahmed M, Rashed CAA. Finite element analysis of one dimensional bio-heat transfer in human tissue. https://doi.org/10.9790/3021-03614349

23. Yue $X$, Wang $L$, Wang $R$ (2013) Tissue modeling and analyzing with finite element method: a review for cranium brain imaging. Int J Biomed Imaging. https://doi.org/10.1155/2013/781603

24. Lin C-T, Liu K-C (2009) Estimation for the heating effect of magnetic nanoparticles in perfused tissues. Int Commun Heat Mass Transf 36:241-244. https://doi.org/10.1016/j.icheatmasstrans fer.2008.11.006

25. Diao C, Zhu L, Wang $\mathrm{H}$ (2003) Cooling and rewarming for brain ischemia or injury: theoretical analysis. Ann Biomed Eng 31:346353. https://doi.org/10.1114/1.1554924
26. Strangman GE, Zhang Q, Li Z (2014) Scalp and skull influence on near infrared photon propagation in the Colin27 brain template. Neuroimage 85:136-149. https://doi.org/10.1016/j.neuroimage .2013.04.090

27. Rast L, Harrison JG (2010) Computational modeling of electromagnetically induced heating of magnetic nanoparticle materials for hyperthermic cancer treatment. PIERS Online 6:690-694. https://doi.org/10.2529/PIERS091218133748

Publisher's Note Springer Nature remains neutral with regard to jurisdictional claims in published maps and institutional affiliations. 